\title{
Reducing Hospital Stays through Subacute and Complex Care Programs
}

\author{
Ronald Lagoe ${ }^{1 *}$, Louise Pernisi², Shelly Littau ${ }^{1}$ \\ ${ }^{1}$ Hospital Executive Council, Syracuse, NY, USA \\ ${ }^{2}$ Upstate University Hospital, Syracuse, NY, USA \\ Email: ${ }^{\text {Hospexcl@cnymail.com }}$
}

Received 11 September 2015; accepted 6 October 2015; published 9 October 2015

Copyright (C) 2015 by authors and Scientific Research Publishing Inc.

This work is licensed under the Creative Commons Attribution International License (CC BY). http://creativecommons.org/licenses/by/4.0/

(c) (i) Open Access

\begin{abstract}
The needs of patients who can stay for extended periods in hospitals generate large amounts of health care expenses. They usually experience multiple diagnoses and their needs are not easily understood or served. This study described the efforts of the acute hospitals in Syracuse, New York to address the needs of these Complex Care patients. The hospitals developed a series of Subacute Programs, each of which addressed a single care need, which might have helped restrain the growth of adult medicine stays during a five-month period. The study demonstrated that reductions in adult medicine stays were associated with the introduction of Complex Care Programs that addressed multiple care needs, in 2015. The association between the implementation of the Complex Care Programs and length of stay reduction for adult medicine was present at the combined and individual hospital levels. The study suggested that the amount of Program Development Funds invested in these programs saved 2000 adult medicine days or $\$ 1,600,000$ compared with total expenses of $\$ 292,000$ during a five-month period. The experiences of the Syracuse hospitals suggested that small programs with simple structures could have a positive impact on health care efficiency at the community level.
\end{abstract}

Keywords

Hospitals, Long Term Care, Hospital Lengths of Stay

\section{Introduction}

In recent years, the importance of efficiency in the movement of patients among health care services has increased. The need for efficiency has been supported by limitations in resources for major health care payors. It

${ }^{*}$ Corresponding author.

How to cite this paper: Lagoe, R., Pernisi, L. and Littau, S. (2015) Reducing Hospital Stays through Subacute and Complex Care Programs. Open Journal of Nursing, 5, 848-854. http://dx.doi.org/10.4236/ojn.2015.510090 
has become especially important for health care organizations that provide episodic care, such as hospitals and physicians [1] [2].

From a financial perspective, efficiency is important because extended stays in hospitals result in large expenses related to patient care. Limitations in reimbursement from health care payors have not covered the cost of care for outlier patients with multiple diagnoses. The impact of these limitations has been heightened by programs such as Accountable Health Care and Bundling [3]-[5].

Efficiency is also important from the perspective of patient outcomes. Patients who stay for extended periods in hospitals have a greater risk of developing inpatient complications than those with shorter stays. Patients whose care needs are addressed fully on inpatient admissions have lower probability of being readmitted [6].

In the United States, one of the greatest challenges to efficiency in hospitals is the complex care or long term acute population. These individuals have clinical conditions that generate extended adult medicine stays, and in some cases, long post operative surgical stays which reduce the efficiency of care at the provider and community levels [3] [7]-[9].

A number of states have developed Long Term Acute Care Programs that provide specific reimbursement to nursing homes and other providers of care of these patients. In some areas, however, these programs are not available. As a result, hospitals and other providers must develop alternatives or provide care to these patients themselves, or they can stay for extended periods and compromise access to hospitals [10]-[12]. This process has frequently required that they develop the resources necessary to support those programs [13].

In this context, relationships between hospitals and nursing homes have become more important than ever. As facilities that provide residential health care on a 24 hour/seven day basis, nursing homes are the only facilities that can provide care for many types of patients who will otherwise remain in hospitals for extended periods of time [14] [15].

\section{Population}

This study evaluated the development of programs addressing long term acute care patients in the metropolitan area of Syracuse, New York. This area includes three acute care facilities (numbers of inpatient discharges for 2014 in parentheses), Crouse Hospital (19,919), St. Joseph's Hospital Health Center $(25,532)$, and Upstate University Hospital $(26,649)$. These hospitals provide primary and secondary services to a service area of approximately 600,000 and referral center services to the eleven county Central New York Health Service area, with a population of $1,400,000$.

Historically, the Syracuse hospitals have worked cooperatively to improve the efficiency and outcomes of care in the local acute care system. A number of these efforts have been undertaken through their planning organization, the Hospital Executive Council [16].

A number of these efforts have focused on reduction of lengths of stay, especially for patients who remain in hospitals for extended periods of time. The hospitals have not developed ownership of large numbers of nursing home beds. Only 14 percent of nursing home beds in the community are hospital owned. Most importantly, New York State has no dedicated program for support of long term acute care patients, such as the programs that exist in a number of states.

\section{Methods}

Between 2003 and 2012, the Syracuse hospitals developed a number of Subacute Programs to support the movement of long term acute care patients from hospitals to nursing homes. The project included the three hospitals and five nursing homes with an interest in caring for these patients. Each of these programs focused on provision of a single service in the participating nursing homes in order to reduce hospital stays. They have included the following.

- Intravenous Medications, including generic, low cost medications;

- Enhanced Medications, including higher cost specific medications;

- Enhanced Plus Medications, including higher cost specific medications and dosages;

- Wound Vac, including extensive wound care equipment;

- Offsite Transport, including transportation for services such as dialysis;

- Bariatric, including support for care of high Body Mass Index patients.

The Subacute Programs have been implemented through agreements between the Syracuse hospitals, local 
nursing homes, and the Hospital Executive Council. These agreements include the following components.

- Certification by an Access Coordinator at each hospital that the need for the program in the community is the principal barrier to discharge;

- A Community Wide Pool of Program Development Funding to support some expenses of care in nursing homes maintained by the Hospital Executive Council;

- Distribution of Program Development Funds for specific types of care, rather than the needs of each patient. Implementation of the Subacute Programs between 2003 and 2012 were useful in restraining the growth of lengths of stay for adult medicine and adult surgery patients in the Syracuse hospitals. At the same time, the impacts of these programs were limited because they focused on a single patient need, rather than multiple issues. To address this need, an additional series of programs addressing multiple Long Term Acute Care or Complex Care requirements were developed and implemented in 2015. These programs have included the following.

- Multiple Intravenous Antibiotics;

- Extensive Wound Care (Wound Vac) Plus Antibiotics;

- Other Combinations of Medications;

- Behavioral Issues Requiring One on One Care;

- Care for Specific Disabilities.

The Complex Care Programs were implemented with the same agreement and components that were used for the Subacute Programs. Program Development Funds included larger amounts of expenses because of the higher care needs of the patients. All of these expenses were funded by the Syracuse hospitals through the Hospital Executive Council.

This study evaluated the impact of the Subacute and Complex Care Programs in the hospitals of Syracuse, New York between March and July 2013 and 2015. This was the most recent three year period for which complete data were available concerning utilization of the programs and their impacts on hospital lengths of stay.

The initial component of the analysis focused on utilization of the individual Subacute and Complex Care Programs during the three five month periods. This analysis included the Subacute Programs in 2013, 2014, and 2015, and the implementation of the Complex Care Programs in 2015. The study data included numbers of patients admitted to nursing homes for the combined hospitals for each individual program as well as for the combined Subacute and Complex Care Programs. This information also included total Program Development Funds expended for the Subacute and the Complex Care Programs combined.

The second component of the analysis focused on the impact of the Subacute and Complex Care Programs on lengths of stay for adult medicine patients discharged to nursing homes from the Syracuse hospitals during March-July 2013, 2014, and 2015. Adult medicine patients were defined as those aged 18 years and over assigned to medicine All Patients Refined Diagnosis Related Groups. The study data included the adult medicine mean length of stay and the severity adjusted All Patients Refined Case Mix Index for each hospital in each five month period.

The third component of the analysis focused on the impact of the Subacute and Complex Care Programs on lengths of stay for adult surgery patients discharged to nursing homes from the Syracuse hospitals during January-June 2013, 2014, and 2015. Adult surgery patients were defined as those aged 18 years and over assigned to surgical All Patients Refined Diagnosis Related Groups. The study data included the same indicators used in the analysis of adult medicine patients.

\section{Results}

The first component of the study focused on utilization of the Subacute and Complex Care Programs in the Syracuse hospitals between March and July 2013 and 2015. Relevant data are summarized in Table 1.

This information demonstrated that the utilization of the Subacute Programs, each of which included a single service, such as a medication or wound care, increased from 35 to 60 between March and July 2013 and 2014, and then remained relatively constant at 60 - 62 patients between March and July 2014 and 2015. Much of the Subacute Program use involved patient medications, including the Intravenous Therapy, Enhanced Medications, and Enhanced Plus Medications.

Utilization of the Subacute Programs for these time periods was reflected in Total Program Development expenses, which more than doubled between March and July 2013 and 2014, then remained relatively constant between the same periods in 2014 and 2015. At the March-July 2015 level, the annualized amount of Subacute Program Expenses would have been \$225,840. 
Table 1. Subacute and complex care program utilization, Syracuse hospitals, March-July 2013-2015.

\begin{tabular}{lccc}
\hline & & Number of Patients & \\
\cline { 2 - 3 } & 2013 & 2014 & \\
\hline Subacute Programs & & & 015 \\
$\quad$ Oral Medications & 6 & 18 & 17 \\
$\quad$ IV Medications & 11 & 9 & 8 \\
Enhanced & 4 & 6 & 8 \\
$\quad$ Enhanced Plus & 2 & 12 & 13 \\
Wound Vac & 5 & 12 & 13 \\
Offsite Transports & 4 & 3 & 3 \\
$\quad$ Bariatric & 3 & & 8 \\
Complex Care Programs & & 0 & 4 \\
$\quad$ Multiple IVs & 0 & 1 & 15 \\
$\quad$ Wound Vac w Meds & 0 & 0 & 4 \\
$\quad$ Behavioral & 0 & 0 & 1 \\
$\quad$ Combined Medications & 0 & 0 & 62 \\
$\quad$ Disability & 35 & 60 & 32 \\
Total Subacute Patients & 0 & 1 & 94 \\
Total Complex Care Patients & 35 & 61 & $\$ 94,100$ \\
Total Subacute \& Complex Care Patients & $\$ 44,850$ & $\$ 98,550$ & $\$ 98,000$ \\
Total Subacute Expenses & $\$ 0$ & $\$ 2800$ & $\$ 192,100$ \\
Total Complex Care Expenses & $\$ 44,850$ & $\$ 101,350$ & \\
Total Expenses & & & \\
\hline
\end{tabular}

The data in Table 1 demonstrated that the introduction of the Complex Care Programs in the Syracuse hospitals resulted in a significant increase in program utilization and costs between March and July 2015. When compared with use of the Subacute Programs, this amounted to a 52 percent rise in total program utilization and an 89.5 percent increase in Program Development expenses. The disproportionate increase in Program Development Expenses resulted from multiple services and resources addressed by the Complex Care Programs.

The data suggested that most of the programs and resources addressed by the Subacute and Complex Care Programs involved adult medicine. The only programs with some involvement for surgical patients were the Wound Care (wound vac) services, where the patient volumes were approximately 50 percent medicine patients and 50 percent surgical patients.

The second component of the analysis focused on the impact of the Subacute and Complex Care Programs on lengths of stay for adult medicine in the Syracuse hospitals. Relevant data are summarized in Table 2.

This information demonstrated that the mean adult medicine length of stay for discharges to nursing homes for the combined hospitals increased from 8.05 to 9.15 days between March and July 2013 and 2014, then declined from 9.15 to 8.32 days between March and July 2014 and 2015. The 2014-2015 decline resulted in a reduction of 2,000 inpatient days. The decline in stays occurred during the period when the Complex Care Programs were implemented. The data also indicated that the severity of illness for this population increased during the three year period.

The information in Table 2 also indicated that the mean adult medicine lengths of stay for discharges to nursing homes for each of the three hospitals increased between March and July 2013 and 2014, then declined between March and July 2014. The largest reductions in stays occurred at Upstate University Hospital where the mean length of stay declined by 2.16 days, resulting in a reduction of 1762 patient days. These declines occurred as the clinical severity of illness for Upstate University Hospital was increasing.

The data suggested that most of the reductions in adult medicine stays for discharges to nursing homes were associated with the implementation of the Complex Care Programs in the Syracuse hospitals during 2015. During this period, most of the increases in stays for this population that occurred between March and July 2013 and 2014 were reversed at each of the three hospitals. The largest reductions in stays occurred at Upstate University Hospital where utilization of the Complex Care Programs was highest. Of the 32 patients admitted to these pro- 
grams during 2015, 20 were discharged from that hospital.

The data in Table 2 concerning total adult medicine discharges also identified the impact of shorter stays for discharges to nursing homes on stays for total discharges for this service. They indicated that the reductions in total adult medicine mean stays for the combined hospitals that occurred between March and July 2014 and 2015 were probably related to the reductions in mean stays for discharges to nursing homes.

The third component of the study evaluated the association between the Subacute and Complex Care Programs on adult surgery lengths of stay in the Syracuse hospitals. Relevant data are summarized in Table 3.

This information demonstrated that the mean adult surgery lengths of stay for discharges to nursing homes for the combined hospitals declined slightly from 10.46 to 10.30 days between March and July 2013 and 2014, then increased slightly from 10.30 to 10.72 days between March and July 2014 and 2015. The increase in stays that occurred during the implementation of the Complex Care Programs, between 2014 and 2015, was associated with an increase of 627 patient days. This compared with the reduction of 2000 adult medicine patient days that occurred during the same period.

The data also indicated that there was no consistent direction in adult surgery stays for discharges to nursing homes from the three hospitals. Lengths of stay for discharges to nursing homes at St. Joseph's Hospital Health Center increased throughout the period, while stays at Upstate University Hospital declined then increased and stays at Crouse Hospital decreased throughout the period.

The data in Table 3 also indicated that, between March and July 2014 and 2015, adult surgery patient days increased by 62.73 at St. Joseph's Hospital Health Center and by 136.53 at Upstate University Hospital while declining by 59.92 at Crouse Hospital. The numbers of these days, both increases and decreases, were considera-

Table 2. Inpatient mean lengths of stay, adult medicine, Syracuse hospitals, March-July 2013-2015.

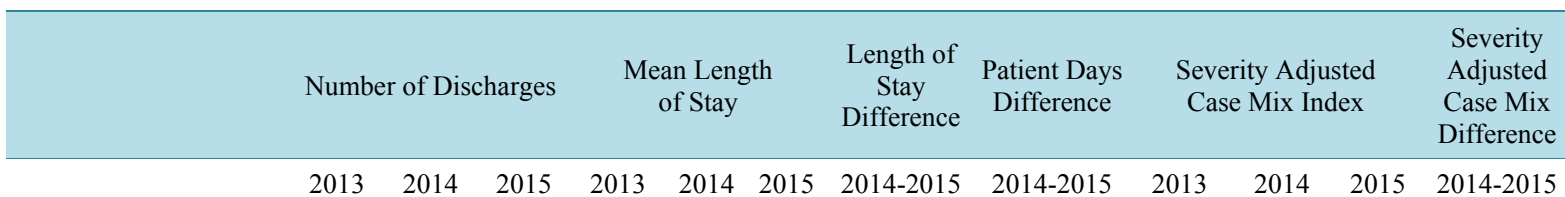

Discharges to

Nursing Homes

\begin{tabular}{|c|c|c|c|c|c|c|c|c|c|c|c|c|}
\hline Crouse Hospital & 527 & 582 & 675 & 7.16 & 7.83 & 7.56 & -0.27 & -182.25 & 1.3273 & 1.2982 & 1.3535 & 0.0553 \\
\hline $\begin{array}{l}\text { St. Joseph's Hospital } \\
\text { Health Center }\end{array}$ & 817 & 804 & 919 & 7.96 & 8.10 & 7.61 & -0.49 & -450.31 & 1.1952 & 1.2198 & 1.1881 & -0.0317 \\
\hline $\begin{array}{l}\text { Upstate University } \\
\text { Hospital-SUNY UMU }\end{array}$ & 636 & 584 & 816 & 8.90 & 11.91 & 9.75 & -2.16 & -1762.56 & 1.4029 & 1.3365 & 1.4582 & 0.1217 \\
\hline Total & 1980 & 1970 & 2410 & 8.05 & 9.15 & 8.32 & -0.83 & -2000.30 & 1.2971 & 1.2775 & 1.3259 & 0.0484 \\
\hline otal Discharges & 14,589 & 14,148 & 14,452 & 5.09 & 5.41 & 5.32 & -0.09 & -1300.68 & 1.0734 & 1.0690 & 1.1317 & 0.0627 \\
\hline
\end{tabular}

Table 3. Inpatient mean lengths of stay, adult surgery, Syracuse hospitals, March-July 2013-2015.

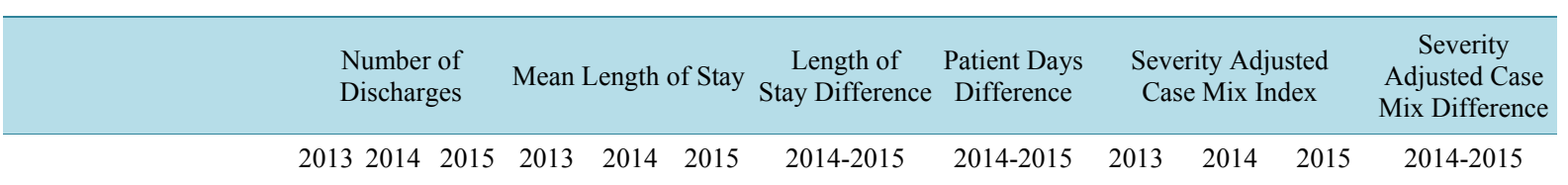

Discharges to

Nursing Homes

\begin{tabular}{|c|c|c|c|c|c|c|c|c|c|c|c|c|}
\hline Crouse Hospital & 263 & 395 & 428 & 7.62 & 6.94 & 6.80 & -0.14 & -59.92 & 2.5131 & 2.2367 & 2.4043 & 0.1676 \\
\hline $\begin{array}{l}\text { St. Joseph's Hospital } \\
\text { Health Center }\end{array}$ & 736 & 673 & 697 & 9.02 & 10.10 & 10.19 & 0.09 & 62.73 & 2.8343 & 2.9099 & 3.1657 & 0.2558 \\
\hline $\begin{array}{l}\text { Upstate University } \\
\text { Hospital-SUNY UMU }\end{array}$ & 243 & 261 & 369 & 17.88 & 15.88 & 16.25 & 0.37 & 136.53 & 3.7826 & 3.2250 & 3.4359 & 0.2109 \\
\hline Total & 1242 & 1329 & 1494 & 10.46 & 10.30 & 10.72 & 0.42 & 627.48 & 2.9518 & 2.7717 & 3.0143 & 0.2426 \\
\hline otal Discharges & 8596 & 8656 & 8711 & 5.87 & 6.22 & 6.31 & 0.09 & 783.99 & 2.3192 & 2.3137 & 2.4072 & 0.0935 \\
\hline
\end{tabular}


bly smaller than the reductions in adult medicine patient days during the same period.

These data suggested the implementation of the Complex Care Programs in the Syracuse hospitals during 2015 were probably not associated with a reduction in adult surgery lengths of stay and patient days. The only facility where reductions in these indicators occurred, Crouse Hospital, admitted six patients to the wound vac programs during this period. The mean length of stay for total discharges to nursing homes also increased throughout the three year period.

\section{Discussion}

The need for efficiency in the delivery of health care continues to increase, especially for providers of short duration care, such as acute hospitals. In this context, the needs of patients who can stay for extended periods present a considerable challenge, both economically and clinically.

The economic challenges of Complex Care or Long Term Acute Care patients are well known in United States hospitals. These patients, through no fault of their own, generate larger amounts of health care expenses than the revenue that they generate. They can also result in costly adverse outcomes such as inpatient complications and readmissions.

At the same time, these patients present a major human challenge to health care providers at the community level. Because they usually experience multiple diagnoses, rather than a single one, their needs are not easily understood or served by a society that tends to deal with health care one need at a time. They are, arguably, the most disadvantaged members of the population.

A number of states have developed Long Term Acute Care Programs to help address the needs of these patients. In areas where these programs are not available, however, individual hospital providers are left to develop their own programs, usually with their own resources, to address their needs.

This study described the efforts of the acute hospitals in Syracuse, New York to address the needs of Complex Care patients without a Long Term Acute Care Program. It described how those hospitals and nursing homes developed a series of Subacute and Complex Care Programs in nursing homes to support shorter stays in hospitals and residential care in a number of nursing homes. These programs were based on relatively simple structures and modest levels of funding.

The results of the study suggested that the Subacute Programs, each of which addressed a single care need, which were developed by the Syracuse hospitals, might have helped restrain the growth of adult medicine stays for discharges to nursing homes between March and July in 2013 and 2014, but were not associated with reductions of these stays. Most of this impact was probably related to the transfer of patient days for individuals receiving intravenous medications from hospitals to nursing homes.

The study data demonstrated that reductions in adult medicine stays for this population were associated with the introduction of the Complex Care Programs, which addressed multiple care needs, in 2015. The association between the implementation of the Complex Care Programs and length of stay reduction for adult medicine was present at the combined and individual hospital levels. The provider with the largest volume of Complex Care patients, Upstate University Hospital, experienced the largest reduction in stays and the largest number of patient days for this service.

The study data suggested that, for the amount of Program Development funds invested in these programs by the Syracuse hospitals, area nursing homes, and the Hospital Executive Council, the return on investment was impressive. At an average per diem expense of $\$ 800$ for a late length of stay day, these programs saved 2000 adult medicine patient days or $\$ 1,600,000$ between March and July in 2015. The total Program Development Funds expended by the Subacute and Complex Care Programs during this period was \$192,100. Adding another $\$ 100,000$ for staffing the programs at the hospitals, nursing homes, and the Hospital Executive Council, total expenses were still only $\$ 292,000$.

The study data also suggested that the impact of Complex Care Programs implemented in Syracuse was largely limited to adult medicine. This probably resulted from the types of therapies, many of which involved medications, included in the programs. No clear association between these programs and reduction of hospital stays for adult surgery could be identified in the study data.

Moving forward, the Syracuse hospitals and the Hospital Executive Council are interested in building on their experience with the Subacute and Complex Care Programs to make further progress in length of stay reduction for adult medicine patients. These efforts will probably include additional Complex Care Programs for total pa- 
renteral nutrition and low level chemotherapy patients. An important component of these efforts is identification of long term care partners who can support these services. These initiatives could reduce the combined hospital stays for adult medicine stays for discharges to nursing homes below eight days. The development of Complex Care Programs for adult surgery patients is also a challenge that will require long term care partners who can support these services.

The need for efficiency in the delivery of health care services will probably continue to shift responsibility for development of these programs to hospitals and other providers. Patients requiring Subacute and Complex Care services will continue to challenge these efforts at the community level. The experiences of the Syracuse hospitals suggest that small programs with simple structures can have a positive impact on efficiency at the community level.

\section{References}

[1] Keehan, S.P., Cuckler, G.A., Sisko, A.M., Madison, A.J., Smith, S.D., Stone, D.A., Poisal, J.A., Wolfe, C.J. and Lizonitz, J.M. (2015) National Health Expenditure Projections, 2014-24: Spending Growth Faster than Recent Trends. Health Affairs, 34, 1407-1417. http://dx.doi.org/10.1377/hlthaff.2015.0600

[2] Dentzler, S. (2011) Urgent Measures for an Old Problem. Health Affairs, 30, 1626. http://dx.doi.org/10.1377/hlthaff.2011.0961

[3] Joynt, K.E., Gawande, A.A., Orav, E.J. and Jha, A.K. (2013) Contribution of Preventable Acute Care Spending to Total Spending for High Cost Medicare Patients. JAMA, 309, 2572-2578. http://dx.doi.org/10.1001/jama.2013.7103

[4] Evans, M. (2012) The Early Returns on Accountable Care. Modern Healthcare, 42, S1-S5.

[5] Fisher, E.S., Shortell, S.M., Kriendler, S.A., Van Citters, A.D. and Larson, B.K. (2012) A Framework for Evaluating the Formation, Implementation, and Accountable Care Organizations. Health Affairs, 31, 2368-2378. http://dx.doi.org/10.1377/hlthaff.2012.0544

[6] Weil, A.R. (2015) Hospital Costs and Quality. Health Affairs, 34, 1263.

[7] Gawande, A.A. (2011) The Hot Spotters: Can We Lower Costs by Giving the Neediest Patients Better Care? New Yorker.

[8] Johnson, T.L., Rinehart, D.J., Durfee, J., Brewer, D., Batal, H., Blum, J., Oronce, C.J. and Melinkovich, P. (2015) For Many Patients Who Use Large Amounts of Health Care Services, The Need Is Intense Yet Temporary. Health Affairs, 34, 1312-1323. http://dx.doi.org/10.1377/hlthaff.2014.1186

[9] Riley, G.F. (2007) Long Term Trends in the Concentration of Medicare Spending. Health Affairs, 26, 808-816. http://dx.doi.org/10.1377/hlthaff.26.3.808

[10] Hasselman, D. (2013) Super Utilizer Summit: Common Themes from Innovative Complex Care Management Programs. Center for Health Care Strategies, Princeton.

[11] Hong, C.S., Siegel, A.L. and Ferris, T.G. (2014) Caring for High Need, High Cost Patients: What Makes for a Successful Care Management Program? Commonwealth Fund, New York.

[12] Bodenheimer, T. (2013) Strategies to Reduce Costs and Improve Care for High Utilizing Medicaid Patients: Reflections on Pioneering Programs. Center for Health Strategies, Princeton.

[13] Lagoe, R., Pernisi, L., Haag, D. and Drapola, B. (2015) Evolution of Programs to Improve Transfers Between Hospitals and Nursing Homes at the Community Level. Open Journal of Nursing, 5, 587-595. http://dx.doi.org/10.4236/ojn.2015.57062

[14] Marek, K.D. and Rantz, M.J. (2000) Aging in Place: A New Model for Long Term Care. Nursing Administration Quarterly, 24, 1-11. http://dx.doi.org/10.1097/00006216-200004000-00003

[15] Wagner, E.H., Austin, B.T., Davis, C., Hindmarsh, M., Schaefer, J. and Bonomi, A. (2001) Improving Chronic Illness Care: Translating Evidence into Action. Health Affairs, 20, 64-78. http://dx.doi.org/10.1377/hlthaff.20.6.64

[16] Lagoe, R., Pasinski, T., Kronenberg, P., Quinn, T. and Schaengold, P. (2005) Linking Health Services at the Community Level. Canada Healthcare Quarterly, 9, 60-65. http://dx.doi.org/10.12927/hcq..18229 